\title{
IDÉIAS
}

\section{Forma de governo de acordo com realidade}

João Gilberto Lucas Coelho

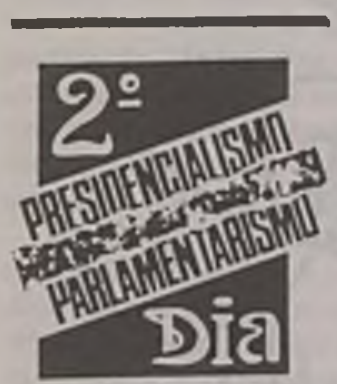

forma presidencialista o conflito entre poderes é insolúvel e em geral conduz à tentativa de desestabilização incondicional de um dos poderes, na forma parlamentar o conflito entre poderes que não possa ser mediado por eles mesmos é devolvido ao voto popular para ser resolvido através de nova eleição. Além disso, a forma parlamentar, o sistema parlamentarista é um sistema de co-responsabilidade entre Executivo e Legislativo enquanto regra quase geral nas formas presidencialistas o Legislativo fica desprovido de poderes mas também de responsabilidades.

Todavia, e na condição de parlamentarista, desejaria reconhecer que a douta explanação do Prof. Young conduz à nós, brasileiros, que vivemos uma outra experiência que não a norte-americana, a uma reflexão preliminar c muito importante.

Antes de decidir sobre forma presidencial ou parlamentar de governo, é preciso que se faça um diagnóstico de que os problemas de governo e de política do Brasil são muito mais da fragilidade, da fraqueza constitucional e concreta da instituição parlamentar e legislativa do que da própria forma de governo. No Brasil nós vivemos uma fragilidade muito grande da instituição legislativa, quer no campo da competência constitucional, quer no campo da sua presença eficaz e concreta no mundo da política e do governo do pais. Por isto, com o presidencialismo ou com o parlamentarismo, é preciso, em primeiro lugar, resolver essa questão da fragili-

João Gilberto Lucas Coelho, advogado, ex ex-deputado federal pelo PMDB do Rio Grande do Sul, Diretor do Centro de Acompanhamento da Constituinte, da UnB.

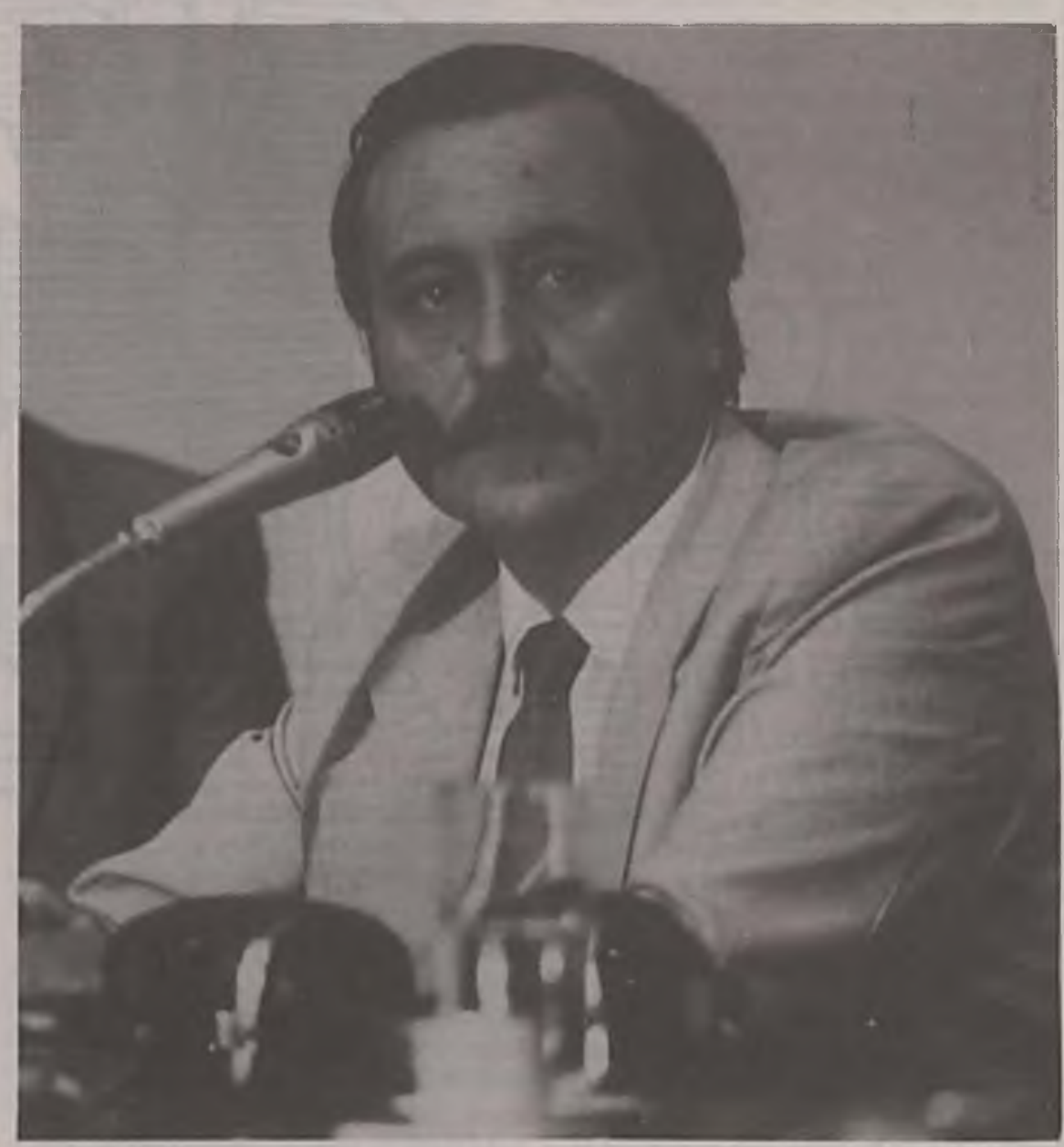

dade da instituição legislativa como um todo no Brasil.

Para abordar o tema permito-me refletir um pouco sobre o presidencialismo brasileiro que temos e para não envolverme nos aspectos que são decorrentes mais da excepcionalidade política do que da forma de governo, eu diria, que, regra geral, com apenas uma exceção, a do decreto-lei, as alusões que faço valem para o presidencialismo do âmbito federal, mas vale também para o presidencialismo dos estados-membros e até da administração presidencialista dos nossos municípios.

O fundamento da fraqueza do legisla. tivo no Município, no Estado e na União, no caso brasileiro, reside no fato de não serem as politicas e os planos de governo decididos pelo Poder Legislativo. Ao contrário de todas as experiências parlamentares de todo o mundo, onde é natural porque o governo sai do Parlamento, mas também o contrário da experiência presidencialista dos EUA, onde a aprovação de políticas e do plano de governo pertence ao Poder Legislativo. No Brasil não. Isto faz com que o Poder Legislativo não tenha concretamente poder, e que então distraia-se em fazer projetos de lei. Nenhum outro parlamento do mundo será tão pródigo em projeto de lei.

Haviam no final do ano passado, oito mil projetos de lei por serem votados em ambas as casas do Congresso brasileiro. 


\section{IDÉIAS}

Estes projetos não significam poder. Enquanto o legislador propõe projetos de lei e talvez até a legislação do pais torne-se num emaranhado pela abundância das leis produzidas e que são muito menos do que os projetos apresentados, o Congresso não tem nenhuma participação na đefinição da política agrícola, na definição da política externa, na definição da política de energia, e assim por diante.

Discordo, profundamente do Embaixador Nascimento e Silva nesse campo. Governo é política e tem que ser feito po. liticamente. Achar-se que burocratas ou os melhores especialistas das nossas universidades ou quaisquer outros, até mesmo aqueles que sejam fardados, possam ser mais competentes do que os políticos para decidir a validade de um programa nuclear, a validade de um programa ferroviário presente hoje nessa discussão, a validade de um programa agrícola não é correto. É a sensibilidade politica que tem que reunir as opiniōes contraditórias dos especialistas, reunir as opiniões que são sempre parciais porque o especialista olha o problema global de um ângulo parcial e dar a globalidade que o político é capaz de dar. Não concordo que o vínculo regional do político local seja regra geral colocado acima dos destinos da nação. Isto pouco acontece, só excepcionalmente acontece. Até mesmo os países que usam o voto distrital e nós nem sequer o voto distrital usamos. Portanto, temos no voto proporcional, no alinhamento por correntes de pensamento, uma base para que o geral, o nacional se sobreponha ao local.

Eu desvio de não votar políticas e não votar planos que transforma o agente político, o representante politico num intermediário dos desvios do nosso sistema que é a nomeação de cargos que são a solução de pequenos problemas na área fisiológica.

Creio que presidencialismo ou parlamentarismo têm que dar ao Poder Legislativo aquilo para qual surgiu o Poder Legislativo. Os cidadãos, os contribuintes, através dos seus representantes eleitos decidirem o que é feito com o seu dinheiro. Se é para construir uma ferrovia ou se é para construir uma série de barragens. Se é para abrir uma estrada ou se é para instalar uma nova usina. Do contrário o próprio caráter do sistema representativo encontra-se comprometido, e no caso brasileiro isto é bem real.

Por outro lado, até mesmo em nossa experiência brasileira, nos três niveis, municipal, estadual e federal, o Poder Legislativo está constrangido. Há uma reserva de iniciativas de leis muito fortes para o Poder Executivo. Só ele pode propor leis em vários casos, por exemplo, todas as leis que impliquem, por exemplo, despesas, todas as leis que tratem de órgãos públicos e assim por diante. $\mathrm{E}$ ainda temos a figura do decreto-lei, que no caso brasileiro, ao contrário de alguns países parlamentaristas que o utilizam, o decreto-lei aqui não é aquela providência emergencial ad referendum do Congresso $\mathrm{Na}$ cional, mas se torna uma possibilidade do Presidente legislar eternamente sobre o mesmo assunto sem que o Congresso possa barrar esta legislação. O presidente faz um decreto-lei sobre determinado assunto, o Congresso dentro de algum tempo o rejeita. Ele renova o decreto-lei sobre o mesmo assunto, o Congresso leva mais um tempo e o rejeita. Ele renova de novo e

Na forma parlamentar, o conflito entre poderes, que não possa ser mediado por eles mesmos, é devolvido ao voto popular para ser resolvido através de nova eleição. É um sistema que induz a co-responsabilidade, entre executivo e legislativo.

assim o que acontece? Pela Constituição brasileira o Congresso não pode analisar os efeitos já produzidos pelo decreto-lei antes da sua rejeição ou ratificação. Então o dispositivo do decreto-lei aqui está cercado de aspectos monárquicos que fazem do presidente um ente com capacidade legislativa de fazer leis contra a vontade do Congresso sem que possa ser interrompido esse ciclo.

$O$ debate atual sobre o parlamentarismo e o presidencialismo tem alguns ingredientes que eu gostaria de analisar.

Creio que a adoção do parlamentarismo, seria a minha vontade pessoal, ou a permanência do presidencialismo tem que ser feitas com características ajustáveis às circunstâncias brasileiras, mas sem comprometer o fundamental desses sistemas, desses regimes de governo, já experimen- tados no mundo.

Existem algumas propostas que criam uma situação tão diferenciada, que comprometida na sua raiz e no seu funcionamento. Por exerrılo, há uma forte corrente entre os constituintes que gostaria de ver uma forma parlamentar de governo em que o Congresso não pudesse ser dissolvido. A meu ver isto é um absurdo.

A base de um regime parlamentar é a co-responsabilidade e é o fato de que, no último momento da crise, no mais sério momento da crise ela possa ser devolvida ao povo para julgamento. Nem o Congresso adquiriria a responsabilidade pelos seus atos, que no presidencialismo nosso atual, o voto a favor ou contra do governo não tem nenhuma responsabilidade, que não talvez a perda da indicação de alguns cargos públicos. $\mathrm{Na}$ forma parlamentarista, o legislador ao votar contra um plano do governo pode estar derrubando o governo, mas pode também estar submetendo o seu mandato à verificação do eleitorado se ele tinha ou não razão nessa atitude.

Este é o cerne do parlamentarismo. Desconhecê-lo ou tentar fazer uma fórmula em que o Congresso possa derrubar o governo, o ministério, o gabinete, mas o presidente não possa recorrer a dissolução e correção de novas eleiçōes, seria criar um novo sistema mais crítico do que o presidencialismo.

Em segundo lugar outra proposta é a que separaria os gabinetes. Haveria um gabinete de governo e um gabinete presidencial. É outro absurdo. Não podem haver ministros ou membros do governo de duas categorias. Alguns submetidos à soberania do Congresso, outros não. Embutido nesta questão, está, sem dúvida, o que eu chamaria a questão militar e que sem ingressarmos na sua análise, nós estaremos apenas tangenciando os problemas ou as instituições brasileiras. Na verdade os militares assumiram um poder político nas instituições brasileiras. Poder político que não é apenas presente numa fase atípica ou institucionalmente excepcional, mas num governo normal. Basta dizer que nós temos seis ministérios, seis ministros que são oriundos das Forças Armadas, ou que são cargos oriundos das Forças Armadas.

Na hora de serem participantes do governo, do conselho de ministro, ou do Conselho de Segurança Nacional, que hoje, na legislação brasileira reúne todos os ministros, os militares são politicos, tanto que temos seis políticos militares nos cargos de ministros. Na hora de como mi- 


\section{IDÉIAS}

nistros políticos serem submetidos à confiança e desconfiança do Congresso, os militares desejam ser instituições permanentes, à parte do processo político e apenas ligadas à Presidência da República.

Não pode haver isto. Ou nós temos um ministério civil da defesa e os comandantes militares que estejam neste ministério, aí sim, serão de nomeação do Presidente da República, mas não terão a personalidade política de ministro, ou nós teremos os ministros militares considerados no bloco político de governo e submetidos à confiança e desconfiança do Congresso Nacional.

Outra alternativa qualquer seria mais germe de crise e seria tangenciar os problemas de organização do poder nacional sem tocá-los devidamente. Por isto, na minha opinião, esta questão de haver um gabinete presidencial e um gabinete de governo não é apenas uma divergência da idéia clássica de parlamentarismo, mas é também uma forma de não encontrarmos um caminho democrático para a construção de novas instituiçōes.

Sobre o debate atual, devo dizer que o Brasil tem oportunidades de repensarse como um todo e que é muito importante que nós estejamos ouvindo experiências de outros países, que nós estejamos discutindo com a nossa própria populaçāo, e que, sobretudo, a Assembléia Nacional Constituinte até aqui tenha manifestado o desejado de ousar, ou seja, tenha manifestado o fiel cumprimento à sua missão. Não estar apegada ao status qua, não estar apegada ao que já existe, mas tentar buscar o que seja melhor para o pais.

Finalmente, desejo contrapor pequenas observaçōes na questão parlamentarismo/presidencialismo. Uma delas, a questão parlamentarismo e federação. Temos federações parlantentaristas no mundo. É bem verdade que menos do que estados unitários. Creio que no Brasil tanto poderia acontecer de se criar a forma parlamentar de governo a nivel federal e estendê-la aos governos estaduais, como poderia acontecer de se ter apenas a forma parlamentar de governo ao nivel da soberania, isto é, na União, e, nos estados-membros, permanecerem com a forma presidencial de governo que possuímos agora.

Recordo que sou de um estado, o Rio Grande do Sul, que intentou em 1946, colocar na sua Constituição e o fez, a forma parlamentar do governo. E a suprema corte, o Supremo Tribunal Federal considerou inconstitucional o Rio Gran- de do Sul adotar o parlamentarismo enquanto que a União adotava o presidencialismo. Acho que este vínculo obrigatório da mesma forma de governo da União ser reproduzido nos estados não é uma questão que seja insolúvel. A Constituição pode adotar os dois sistemas se este for o desejo ou pode até deixar a liberdade dos estados irem se organizando sobre a forma parlamentar ou sobre a forma presidencial.

A questão bem grave que inclusive o nosso Ministro Aluízio Alves advertia, sem dúvidas, é a questão que o Brasil tem milhares de cargos em comissão, milhares de cargos de preenchimento atípico, sejam por contratos, sejam por outras fórmulas e que estes cargos costumam mudar cada vez que muda o governo. E nem

Antes de discutir a forma presidencial ou parlamentar de governo, é preciso que se faça um diagnóstico de que os problemas de governo e de política no Brasil são muito mais da fragilidade constitucional do que da forma de governo.

poderia ser diferente. Se o preenchimento não é pelo concurso público, portanto, se ele, num determinado governo está sob a influência seja de um partido politico, seja de uma corrente militar, seja de uma corrente burocrática, se eles foram preenchidos desta forma por quem detêm eventualmente o governo ou a influência sobre o governo, é claro que eles têm que mudar quando muda o governo.

Todavia esta pluralidade, esta riqueza de cargos em comissão, pior do que isto, dos cargos via contratos, dos cargos das estatais, etc., é uma questão atípica e é uma questão errada, seja no presidencialismo, seja no parlamentarismo. Então nós devemos, paralelamente a este esforço de construir nova forma de governo, nós também devemos, e o ministro inclusive tem manifestado essa preocupação de criar um quadro funcional de caráter mais permanente, mas cujo ingresso não seja como ontem era. $\mathrm{O}$ apadrinhamento com um eventual comandante militar ou com um eventual chefe burocrático, hoje, o apadrinhamento com representação política partidária.

Acho que isto compromete muito. Em setores vitais, a Previdência Social, por exemplo, o fato da Previdência Social ter a nível de municípios, o seu preenchimento feito por influência de chefias políticas ou de chefias de poder, seja qual for o tipo é algo que compromete profundamente, até porque a Previdência Social não é um aparelho de governo, é muito mais a cogestão de seus associados e é um fundo que visa a dar seguridade social aos que são membros e filiados a este fundo.

Confesso que, tendo desejo profundo de ver o país caminhar para uma forma parlamentar de governo, reconheço que a mentalidade do cidadão brasileiro, da cidadã brasileira ainda é muito presidencialista a nivel das mínimas reaçōes.

Talvez seja muito latino-americano de nossa parte, mas nós estamos sempre querendo eleger alguém nas mãos do qual nós desejamos entregar nosso destino. Os professores querem eleger o diretor da escola, não querem cogerir a escola. Seria diferente, como acertadamente a Constituição espanhola disse: "A escola é cogerida pelos que dela fazem parte".

Nós estamos querendo eleger o reitor da universidade mesmo que para os mesmos que o elegem façam greve contra ele no dia seguinte a sua posse. Nós queremos eleger todos os cargos possíveis. Mas não é eleger para cogerir com o eleito. É eleger para entregar nas suas mãos o nosso destino e para cobrar somente dele, não de cada um de nós, a solução de nossos problemas. Creio até que a introdução de uma experiência parlamentarista, sem casuísmos, sem vínculos a este ou aquele presidente, mas como um projeto novo nacional, influenciará profundamente na mudança desta distorcida mentalidade que é uma mentalidade do caudilhismo ainda, é uma herança do caudilhismo, entregar o futuro nas mãos de um caudílho, mesmo que depois, guerrear contra ele.

Esta a minha contribuição a este debate e dizendo que ele é construtivo e ele está na linha desta abertura que a Assembléia Nacional Constituinte dá e que o Brasil está se repensando e que nós somos capazes de construir algo novo para nossa população e buscar novas instituições e de buscar escapar dos vícios e dos limites que até aqui tivemos." 